\title{
Learning Curve for a Laparoscopic Appendectomy by a Surgical Trainee
}

\author{
Song Yi Kim, Sung Gun Hong, Hye Rin Roh, Seong Bae Park, Yang Hee Kim, Gi Bong Chae \\ Department of Surgery, Kangwon National University School of Medicine, Chuncheon, Korea
}

Purpose: The laparoscopic appendectomy has been a basic part of the principal of a more complex laparoscopic technique for the surgical trainee. As the number of laparoscopic appendectomies performed by surgical trainees has increased, we are trying to check the stability of, which is controversial, and the learning curve associated with a laparoscopic appendectomy.

Methods: We studied the demographics, histologic diagnoses, operative time, the number of complicated cases, and hospital duration of one hundred and three patients who underwent an open appendectomy (group A, 53) or a laparoscopic appendectomy (group B, 50) retrospectively through a review of their medical records. The learning curve for the laparoscopic appendectomy was established through the moving average and ANOVA methods.

Results: There were no differences in the operative times (A, $64.15 \pm 29.88$ minutes; B, $58.2 \pm 20.72$ minutes; P-value, 0.225 ) and complications (A, 11\%; B, 6\%; P-value, 0.34) between group A and group B. Group B was divided into group C who underwent the operation in the early period (before the learning curve) and group $\mathrm{D}$ who underwent the operation in the later period (after the learning curve). The average operative time for group $C$ was $66.83 \pm 21.55$ minutes, but it was 45.25 \pm 10.19 minutes for group D (P-value $<0.0001$ ). Although this difference was statistically significant, no significant difference in the complication rate was observed between the two groups.

Conclusion: A laparoscopic appendectomy, compared with an open appendectomy, performed by a surgical trainee is safe. In this study, the learning curve for a laparoscopic appendectomy was thirty cases.

\section{Keywords: Appendectomy; Laparoscopy; Learning curve}

\section{INTRODUCTION}

In 1886, acute appendicitis was revealed to be the first causative of right low quadrant (RLQ) pain by Reginald Fitz, and surgical treatments at the time of diagnosis became the common treatment mode [1]. A laparoscopic appendectomy was performed for the first time in 1983 by Semm [2]. It came to be known by patients and guardians gradually, but now it has become the basic surgery for acute appendicitis.

Received: May 8, 2010 Accepted: September 28, 2010

Correspondence to: Gi Bong Chae, M.D.

Department of Surgery, Kangwon National University School of Medicine,

192-1 Hyoja 2-dong, Chuncheon 200-701, Korea

Tel: +82-33-258-2306, Fax:+82-33-258-2169

E-mail: cgb3377@kangwon.ac.kr

(c) 2010 The Korean Society of Coloproctology

This is an open-access article distributed under the terms of the Creative Commons Attribution NonCommercial License (http://creativecommons.org/licenses/by-nc/3.0) which permits unrestricted non-

commercial use, distribution, and reproduction in any medium, provided the original work is properly cited.
The safety of a laparoscopic appendectomy is already widely accepted, and it is a surgical method known to have the advantages of fast recovery, reduction of postsurgical pain and the risk of infection, and enhanced esthetic effects $[3,4]$. For surgical residents, performing a laparoscopic appendectomy has become the basis for acquiring the basic principles of more complex laparoscopic surgery.

In the past several years, a large number of acute appendicitis patients admitted to hospitals have chosen a laparoscopic appendectomy; thus, the frequency of appendectomies performed by surgical residents is on the rise. Due to the increased number of laparoscopic appendectomies performed by surgical residents, issues concerning the safety of surgery have increased, and although the safety of surgery performed by residents in the Department of Surgery, after a certain learning curve, has already been demonstrated in several previous studies, studies on the learning curve are not abundant [5]. By comparing the surgical outcomes and complications of an open appendectomy with those of a laparoscopic appendectomy, 
we suggest a standard for the learning curve of a laparoscopic appendectomy.

\section{METHODS}

\section{Subjects}

The subjects were 111 patients who underwent surgery in the Department of Surgery, Kangwon National University Hospital, from March 2008 to December 2008. As the research method, medical records, pathological results, and tests performed at the time of admission were examined retrospectively.

At the time of admission, surgical methods were determined by considering the underlying diseases and general conditions of the patients, and in cases in which perforated appendicitis had been diagnosed on pre-surgical examination, an open appendectomy was performed. Regardless of the method of surgery, surgeries were performed by a single resident under the supervision of a surgeon. The resident who performed the surgery was a second year resident who had performed more than 30 open appendectomies prior to performing a laparoscopic appendectomy, and he was the attending physician of the patients who underwent open, as well as laparoscopic, appendectomies from March 2008 to December 2008.

Among the 111 patients, the medical records of 2 patients were not sufficient; thus, they were excluded. In the patient group who received an open appendectomy, 6 patients who received spinal and epidural anesthesia were excluded. The mean age of the remaining 103 patients was 34.6 years (range, 5 to 87 years), the number of males was $58(56.3 \%)$, and the number of females was 45 (43.7\%). Among the 103 patients, a laparoscopic appendectomy was performed on 50 patients, and an open appendectomy was performed on 53 patients. The patient group receiving an open appendectomy was called group $\mathrm{A}$, and the patient group receiving a laparoscopic appendectomy was called group B. By obtaining the consecutive moving average, 30 patients who underwent a laparoscopic appendectomy in the early period (before the learning curve) were identified as group $\mathrm{C}$, and 20 patients who underwent a laparoscopic appendectomy later (after the learning curve) were identified as group D.

\section{Surgical methods}

In the open appendectomies, the transverse incision performed by Davis-Rokey was applied, and blood vessels and adjacent tissues were sutured with black silk 3-0. In the appendectomy, ligation was performed using black silk 2-0 $[6,7]$. In the laparoscopic appendectomies, three trocars $(10 \mathrm{~mm}, 5 \mathrm{~mm}$, and 5 $\mathrm{mm}$ ) were used. A $10-\mathrm{mm}$ trocar was inserted into the area below the navel, a 5-mm trocar was inserted into the left lower abdomen, and another 5-mm trocar was inserted into the suprapubic area.

The laparoscope was inserted by using an open method, and for the ligation of blood vessels, the vessel sealing system (Ligasure, Covidien, Boulder, CO, USA) was used. For the resection of the appendix, the base was ligated using the Vicryl endoloop, and for the distal area, the leakage was blocked using clips. Afterwards, the resected appendix was inserted into a specimen retrieval bag and removed from the abdominal cavity through the insertion site of the $10-\mathrm{mm}$ trocar $[1,6]$.

According to pathological results, acute appendicitis was classified as acute early focal appendicitis, acute suppurative appendicitis, acute gangrenous appendicitis, and perforated appendicitis. The pathological grades were determined by the progression level of inflammation. Early acute appendicitis is 1 point, acute suppurative appendicitis is 2 points, acute necrotic appendicitis is 3 points, and perforated appendicitis is 4 points.

\section{Statistics}

Through a consecutive comparison of operation times, the trend in the changes was analyzed, the moving average was used to predict a learning curve, and the two groups, one prior to and one after the predicted learning curve, were analyzed by using the ANOVA (SPSS ver. 18.0, SPSS Inc., Chicago, IL, USA) program. Cases with P-values $<0.05$ were determined to be statistically significant.

\section{RESULTS}

Comparison of the results of the group who received an open appendectomy $(\mathrm{A})$ with the group who received a laparoscopic appendectomy (B)

The mean ages of the group A and the group B were $40.39 \pm$ 22.16 years and $27.76 \pm 15.76$ years, respectively, and a statistically significant difference was shown (P-value, 0.001 ). No difference in the gender ratios of group $A$ and group $B$ was detected (P-value, 0.74 ). The average operation time of group A was $64.41 \pm 29.88$ minutes and that of group B was $58.20 \pm$ 20.72 minutes, but this difference was not significant (P-value, 0.225 ).

The classification of acute appendicitis was converted to a score based on the pathological diagnosis, the score of group A was 2.26 points, that of group B was 1.96 points, a significant difference (P-value, 0.034) (Table 1). The incidences of early focal appendicitis, acute suppurative appendicitis, and acute gangrenous appendicitis of the two groups were not different, but the incidence of perforated appendicitis of the two groups did show a difference (P-value, 0.018).

The average hospitalization period of group A was $5.26 \pm 2.09$ days, and that of group B was $3.7 \pm 1.51$ days, which was significantly shorter for group A (P-value $<0.001)$. Postsurgical complications in group A occurred in 6 cases (11\%), and those in group B occurred in 3 cases (6\%), but this difference was not significant (P-value, 0.34) (Table 2). 
In regard to the complications that developed in the group A after surgery, heart failure occurred in 1 case, a myocardial infarction in 1 case, acute renal failure in 1 case, surgical wound infection in 2 cases, and death after surgery in 1 case. In the group B, surgical wound infection occurred in 3 cases, and all wound infections developed in the area through which the $10-\mathrm{mm}$ trocar had been inserted.

\section{Results of group B who received a laparoscopic appendectomy compared to the result of the moving average}

Group B, who received a laparoscopic appendectomy, was divided into 5 groups, 10 patients each, according to the order of the time at which the surgery was performed, assigned as groups 1, 2, 3, 4, and 5, and the moving average was obtained (Fig. 1). At the time of the transition from group 2 to group 3, a shortening of the operation time was shown. Between group 2 and group, 3 no significant difference in the average operation times was shown. A significant difference in the average operation times between group 3 and group 4 (P-value, 0.026), as well as between group 3 and group 5 ( $\mathrm{P}$-value $<0.006$ ) was shown; thus, one could hypothesize that the learning curve is 30 cases.

Comparison of the result of the early group (C) and the late group (D) who received a laparoscopic appendectomy

Assuming that the learning curve is 30 cases based on the moving average, the group prior to the learning curve was defined

Table 1. Comparison of demographics

\begin{tabular}{lccc}
\hline & Group A & Group B & P-value \\
\hline No. of patients & 53 & 50 & \\
Mean age of patients (yr) & $40.39 \pm$ & $27.76 \pm$ & 0.001 \\
& 22.16 & 15.76 & \\
Male & $29(54)$ & $29(58)$ & 0.74 \\
Histological diagnosis & & & \\
Early focal appendicitis & $6(11)$ & $6(11)$ & 0.686 \\
Acute suppurative appendicitis & $35(66)$ & $40(80)$ & 0.181 \\
Acute gangrenous appendicitis & $4(7)$ & $3(6)$ & 0.758 \\
Perforated appendicitis & $8(16)$ & $1(2)$ & 0.018 \\
Score & 2.26 & 1.96 & 0.034 \\
\hline
\end{tabular}

Values are presented as number (\%) unless otherwise indicated.

Table 2. Outcome variables of group A and group B

\begin{tabular}{lccr}
\hline & Group A & Group B & P-value \\
\hline $\begin{array}{l}\text { Mean operative duration } \\
\text { (min) }\end{array}$ & $64.41 \pm 29.88$ & $58.20 \pm 20.72$ & 0.225 \\
Complication rate (n, \%) & $6(11)$ & $3(6)$ & 0.34 \\
$\begin{array}{l}\text { Mean length of stay } \\
\text { (day) }\end{array}$ & $5.26 \pm 2.09$ & $3.7 \pm 1.51$ & $<0.001$ \\
\hline
\end{tabular}

as $C$ group and that after the learning curve was defined as group $\mathrm{D}$, and the differences between the two groups were analyzed by using the ANOVA program. Between group $C$ and group $\mathrm{D}$, the age ( $\mathrm{P}$-value, 0.77$)$ and the gender ( $\mathrm{P}$-value, $0.053)$ were not statistically different. The average operation time of $C$ group was $66.83 \pm 21.55$ minutes, and that of $\mathrm{D}$ group was $45.25 \pm 10.19$ minutes, which is a statistically significantly difference (P-value $<0.0001)$. In group $\mathrm{C}$, complications developed in 3 cases, and in the group $\mathrm{D}$, complications were not shown (P-value, 0.151). In addition, significant differences were not shown in the hospitalization period and histological examination; thus, 30 cases could, indeed, be defined as the learning curve (Table 3, Fig. 2)

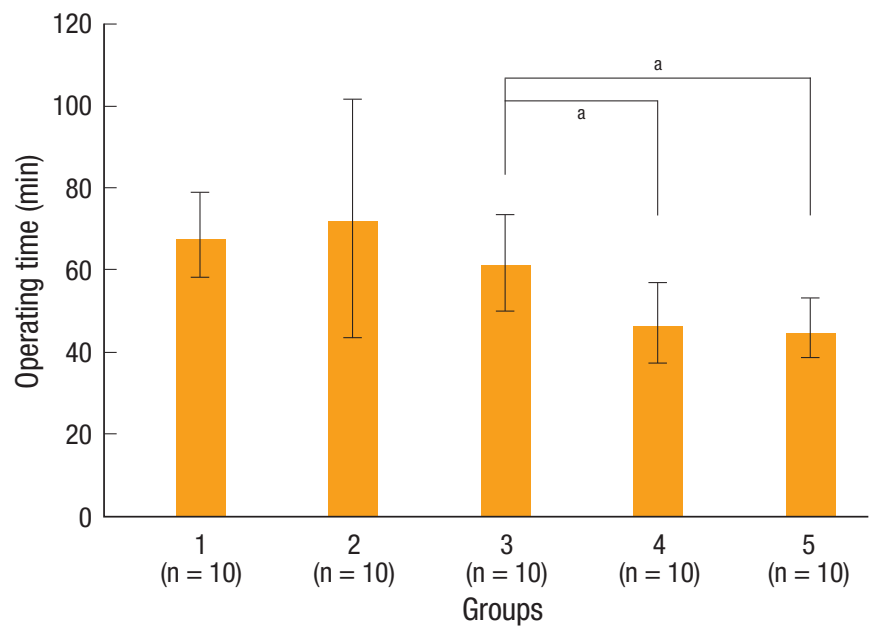

Fig. 1. Operating times for the moving average method for consecutive groups of ten patients (mean \pm SEM): group 1, $67.50 \pm 11.84$; group 2, $72.00 \pm 32.68$; group 3, $61.00 \pm 14.87$; group 4, $46.00 \pm 12.65$; group $5,44.50 \pm 7.62 .{ }^{\text {a }}$-value $<0.05$.

Table 3. Outcome variables of the initial laparoscopic appendectomy (group C) and the subsequent laparoscopic appendectomy (group D) groups

\begin{tabular}{|c|c|c|c|}
\hline & Group C & Group D & P-value \\
\hline Cases & Initial 30 & Subsequent 20 & \\
\hline $\begin{array}{l}\text { Mean age of patients } \\
(\mathrm{yr})\end{array}$ & $30.90 \pm 16.85$ & $23.05 \pm 11.78$ & 0.077 \\
\hline Male $^{\mathrm{a}}$ & $13(43)$ & $8(40)$ & 0.820 \\
\hline $\begin{array}{l}\text { Mean operative } \\
\text { duration (min) }\end{array}$ & $66.83 \pm 21.55$ & $45.25 \pm 10.19$ & $<0.0001$ \\
\hline Complication rate ${ }^{a}$ & $3(10)$ & $0(0)$ & 0.151 \\
\hline Conversion rate ${ }^{a}$ & $0(0)$ & $0(0)$ & \\
\hline Length of stay (day) & $3.70 \pm 1.11$ & $3.45 \pm 1.98$ & 0.572 \\
\hline
\end{tabular}

${ }^{a}$ Values are presented as number (\%). 

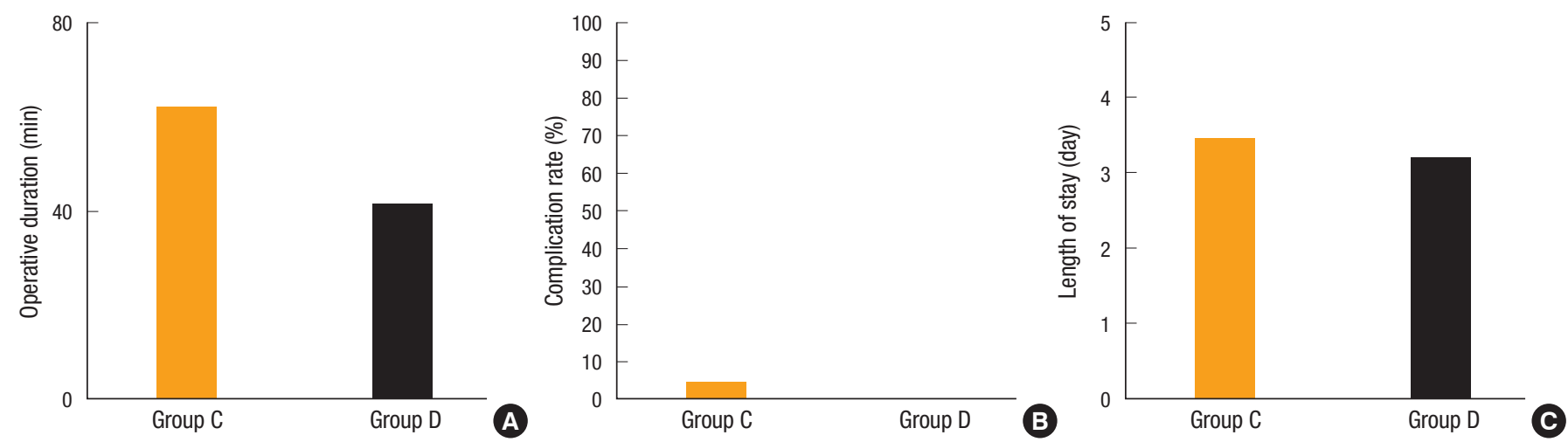

Fig. 2. Outcomes for the variables, as determined by using ANOVA method: (A) mean operative duration (P-value $<0.0001)$, (B) complication rate (\%) (P-value, 0.151$)$, and (C) length of stay (P-value, 0.572$)$.

\section{DISCUSSION}

Acute appendicitis is a representative disease of acute abdomen and requires early diagnosis and surgical treatment. The incidence of acute appendicitis is approximately $7 \%$, and in comparison with other diseases, its incidence is high, so it is a disease that is frequently observed [6].

For surgical residents, acute appendicitis is a disease encountered frequently during the course of becoming surgeons. Through acute appendicitis patients, the resident is exposed to a series of decisions from diagnosis and treatment to surgery.

Appendectomy facilitates the acquisition of basic surgical techniques; furthermore, it provides basic techniques pertinent to other important operations. However, due to the expansion of the concepts of micro-invasive surgery, improvement of quality of life, etc., the trend is to favor a laparoscopic appendectomy over an open appendectomy. Therefore, the laparoscopic appendectomy is becoming a basic surgical technique that surgical residents should acquire [8].

When surgical residents perform a laparoscopic appendectomy, the question asked is 'whether the surgery performed by surgical residents is safe and shows good results?' To answer the question, the learning curve was defined, and laparoscopic appendectomies performed by residents beyond the learning curve have been reported to be safe [9]. Twenty cases were suggested as the learning curve by the European Association for Endoscopic Surgeons. In a study reported by Lin [2], as residents acquire more experiences, the operation time and the rate of the conversion to a laparotomy were shown to be reduced.

For a learning curve of 20 cases, as suggested by the European Association for Endoscopic Surgeons, the average operation times of group 1 and group 2 and of group 3 and group 4 were compared, $69.75 \pm 24.03$ minutes and $53.50 \pm 15.48 \mathrm{~min}-$ utes, respectively, and were found to be significantly different (P-value, 0.015). However, the average operation times of group
3 and group 4 were greatly different, and the cumulative average of the two groups decreased; thus, the analysis results could be changed.

In our study, on the assumption that the operation time prior to the learning curve should always show a significant difference from the operation time after the learning curve, laparoscopic appendectomy cases performed by a single surgical residents were divided to 5 subgroups, 10 cases each, and the consecutive moving averages of the operation times were compared [5]. The operation times between groups 3 and 4 (Pvalue, 0.026$)$ and between groups 3 and 5 (P-value $<0.006$ ) showed continuous significant differences. When the cumulative operation time of groups 1,2, and 3 was compared with the cumulative operation time of groups 4 and 5, 66.83 \pm 21.55 minutes and $45.25 \pm 10.19$ minutes, respectively, a statistically significant difference was shown (P-value $<0.0001)$. Based on this, the learning curve was defined as 30 cases, the groups prior to and after the learning curve were defined, and the results for those groups were examined.

Complications occurred in a total of 3 cases. In comparison with the complications shown in the study reported by Pasquini [8], Rezola [9], no great difference was detected (5.2\% vs. 5.5\%). Nonetheless, different from the results of other studies, complications did not develop in the surgeries performed after the learning curve, and none of the surgeries was converted to a laparotomy. Based on the absences of complications and of conversions to a laparotomy, the learning curve is suggested to be 30 cases.

A characteristic of our study was that in pathohistological tests, the incidence of perforated appendicitis between the groups was different, and in open appendectomies, the incidence of perforated appendicitis was shown to be significantly higher than it was in laparoscopic appendectomies. In group A, the operation time of the patients diagnosed as having a perforated appendicitis was $96.50 \pm 42.955$ minutes, and the operation time of the other patients was $58.71 \pm 23.27 \mathrm{~min}$ utes, a significant difference (P-value, 0.001). However, in group 
B, only 1 patient was diagnosed as having a perforated appendicitis $(2 \%)$, so the effect on the operation time could not be assessed.

When the complications, operation times, and pathohistological diagnoses of the group on whom an open appendectomy (group A) had been performed and the group on whom a laparoscopic appendectomy (group B) had been performed were compared, the operation times, pathohistological diagnoses of appendicitis, and complications did not show differences; thus, a laparoscopic appendectomy performed by surgical residents was found to be safe. Based on the observation that in comparisons with the group receiving a laparoscopic appendectomy in an early period (group C), the operation time of the group who received laparoscopic surgery in a later period (group D) was significantly shortened, and complications and conversion to laparotomy were absent, the learning curve of a laparoscopic appendectomy could be defined as 30 cases.

Because this study is the result of an analysis of surgeries performed by a single resident, it has limitations in suggesting a learning curve for all surgical residents. Therefore, if a consistent the learning curve is to be found, future studies that accurately define the learning curve by analyzing surgeries performed by several residents are required, and the bias of the early surgical methods and the selection of the patient groups are must be corrected.

\section{CONFLICT OF INTEREST}

No potential conflict of interest relevant to this article was reported.

\section{REFERENCES}

1. John MA, Kimberly SK. The appendix. In: Townsend CM Jr, Beauchamp RD, Evers BM, Mattox KL, editors. Sabiston textbook of surgery: the biological basis of modern surgical practice. 18th ed. Philadelphia: W.B. Saunders; 2008. p.917-73.

2. Lin YY, Shabbir A, So JB. Laparoscopic appendectomy by residents: evaluating outcomes and learning curve. Surg Endosc 2010;24:125-30.

3. Minne L, Varner D, Burnell A, Ratzer E, Clark J, Haun W. Laparoscopic vs open appendectomy. Prospective randomized study of outcomes. Arch Surg 1997;132:708-11.

4. Chiu CC, Wei PL, Wang W, Chen RJ, Chen TC, Lee WJ, et al. Role of appendectomy in laparoscopic training. J Laparoendosc Adv Surg Tech A 2006;16:113-8.

5. Jaffer U, Cameron AE. Laparoscopic appendectomy: a junior trainee's learning curve. JSLS 2008;12:288-91.

6. Smink DS, Soybel DI. Appendix and appendectomy. In: Zinner MJ, Ashley SW, editors. Maingot's abdorminal operations. 11th ed. New York: Mcgraw-Hill Co; 2007. p.589-612.

7. Jaffer BM, Berger DH. The appendix. In: Schwartz SI, Brunicardi FC, editors. Schwartz's principles of surgery. New York: McGrawHill; 2010. p. 1073-86.

8. Pasquini G, Rubino F, Bruni V, Martinengo L, Mazzarella P, Amodio PM, et al. Laparoscopic appendectomy: retrospective studies of 172 consecutive procedures. Chir Ital 2004;56:257-60.

9. Rezola E, Villanueva A, Garay J, Sunol M, Arana J, Intxaurrondo MI, et al. Laparoscopic appendectomy after the learning curve. Cir Pediatr 2008;21:167-72. 